\title{
Application of X-ray Diffraction for Residual Stress Analysis in Truncated Cones Made by Incremental Forming
}

\author{
Bogdan Krasowski ${ }^{1}$, Andrzej Kubit ${ }^{2}$, Tomasz Trzepieciński ${ }^{3 *}$, \\ Kazimiera Dudek ${ }^{4}$, Jan Slota ${ }^{5}$ \\ 1 State School of Higher Vocational Education, Krosno, Poland \\ ${ }^{2}$ Department of Manufacturing and Production Engineering, Rzeszow University of Technology, Rzeszów, \\ Poland \\ ${ }^{3}$ Department of Materials Forming and Processing, Rzeszow University of Technology, Rzeszów, Poland \\ ${ }^{4}$ Department of Mechanics and Machine Building, University of Rzeszow, Rzeszów, Poland \\ ${ }^{5}$ Institute of Technology and Material Engineering, Faculty of Mechanical Engineering, Technical University of \\ Košice, Košice, Slovakia \\ * Corresponding author's e-mail: tomtrz@prz.edu.pl
}

\begin{abstract}
The final accuracy of the parts formed using single point incremental forming greatly depends on the mechanical properties of the material to be formed and the residual stress formation. In this paper, an X-ray diffraction technique was used to study the distribution of the residual stress along the generating line of the conical drawpiece. A DC04 steel sheet with a thickness of $0.8 \mathrm{~mm}$ was used as a test material. The basic mechanical properties of the DC04 sheet metal were determined in the uniaxial tensile test according to the EN ISO 6892-1:2016. It was found that the maximum amount of the residual stress existed in a point located in the midway between a base and a truncation of the drawpiece. In the outer surface of the drawpiece, the orange peel defect associated with a rough surface appearance after SPIF a drawpiece, was observed. In contrast, the inner surface of component was characterized by linear grooves associated with the interaction of tool tip with the sheet surface. This defect is mainly influenced by vertical step size.
\end{abstract}

Keywords: drawpiece, incremental forming, ISF, steel sheet

\section{INTRODUCTION}

Single Point Incremental Forming (SPIF) works on the principle of step-by-step repeating local small deformations and producing the desired geometry. Due to the local character of the deformation, the SPIF process requires smaller capacity than that in conventional sheet forming (CSF). Most of the SPIF processes are conducted with a rigid rounded tool with different tip shapes. The formability of the sheet in SPIF depends on the following process parameters: contact conditions, a sheet thickness, a size of the vertical step size, a feed rate, a tool path strategy, tool rotation speed and a radius of a tool tip.
SPIF is the most frequently used incremental forming method, more than any other type of ISF in the recent years: Two point incremental forming, double-side incremental forming, positive incremental forming, negative incremental forming, water jet sheet incremental forming. The advantages of using the incremental forming method is a higher deformation degree than in CSF, a possible higher deformation of materials with reduced susceptibility to cracking [1]. ISF is characterized by the ability to form workpieces on a conventional computer numerical control (CNC) milling machine. However, SPIF requires longer duration of forming times compared to the CSF techniques. ISF is a suitable technology for the preparation of 
prototypes and low volume production. The accuracy of drawpieces formed with SPIF strongly depends on the springback phenomenon. Deviation between the designed target shape and manufactured part shape due to springback of drawpiece material after forming may be minimized using the tool path correction algorithms.

Recently, a number of investigations of the ISF processes were conducted to study the effect of the forming parameters on the final quality of the drawpieces. Kumar et al. [10] investigated the effect of the process parameters on the average surface roughness of the AA2024-O sheets. They found that a decrease in a tool diameter leads to an increase in the average roughness. Attanasio et al. [2] studied the effect of step size on surface roughness. It was found that a constant scallop height with varying step size produced a better surface quality. Durante et al. [5] found that surface roughness decreases when tool speed passed from the not rotating to rotating conditions. Li et al. [11] analysed the effect of process variables on the forming time, the power and energy required for SPIF. It was concluded that it is beneficial for energy saving to increase the feed rate and step size. Xu et al. [20] investigated the influence of the textured tool rotation on the ISF process and found that the through-the-thickness shear is a positive factor for the formability improvement. Friction in the ISF process can be reduced by replacing the rotational rigid tool with a rollerbased tool. The advantages of the roller-based tool include lower forming load and higher formability [12].

The SPIF is characterized by its localised plastic strain which allows the workpiece to be stretched well beyond the conventional forming limit curves [14]. Thus, a high magnitude of the residual stresses is always inherent to the SPIF processes. There are many techniques allowed to measure residual stresses. A few of them are: Raman spectroscopy, ultrasonic method, nanoindentation, X-ray diffraction (XRD), and hole drilling. Recently, X-ray diffraction was the most used method for measuring residual stresses. Maaß et al. [13] used X-ray diffraction to study the effect of the dominant forming mechanisms on the residual stress state of the component manufactured from 5083 aluminium alloy sheets. Different tool strategies were considered to investigate the residual stress development. It was found that the effect of the tool path strategy on the amplitude of the resulting residual stress is unincisive. Jiménez et al. [7] studied the residual stresses in truncated pyramids made of aluminium alloy sheets which were formed by ISF using the X-ray diffractometer. The change of residual stresses from tensile to compression along the formed part is assumed to be an indicator of bending effects. Bedan et al. [3] found that the high values of the vertical step size led to the high values of the residual stresses, which in turn caused the high values of standard deviations of the formed parts geometry from the desired geometry.

In this paper, the state of the residual stresses induced in the ISF parts made of 0.8 -mm-thick DC04 steel sheets was investigated. The outer surface of conical truncated drawpieces was measured at different angles using an X-ray XSTRESS3000G3R diffractometer. Moreover, the surface roughness of the inner and outer surface of the drawpieces was analysed using a Contour GT 3D optical microscope.

\section{MATERIALS AND METHODS}

The 0.8-mm-thick DC04 low carbon steel sheet was used as a test material. This steel is characterized by good ability to deformation and is commonly used for the fabrication of automotive body parts. The chemical composition of the sheet tested according to the EN 10130:2006 standard is listed in Table 1.

The mechanical properties of the sheet metal, i.e. yield stress $R_{p 0,2}$, ultimate tensile stress $R_{m}$ and elongation $\mathrm{A}_{50}$, were determined through the uniaxial tensile test. The tests were carried out according to the ENISO892-1 standard. The specimens for tensile tests were cut along three directions with respect to the rolling direction. The mechanical parameters of the DC04 sheet and standard deviations are presented in Table 2 below. Three specimens were tested for each specimen orientation. The relationship between the strength coefficient $K$ and strain hardening exponent $n$ and of the material during uniaxial stretching can be indicated by the Hollomon formulae:

$$
\sigma_{p}=K \cdot \varepsilon^{n}
$$

where: $\sigma_{p}$ is the yield stress, $\varepsilon$ is the true strain.

Table 1. Chemical composition (wt.\%) of DC04 sheet metal

\begin{tabular}{|c|c|c|c|c|}
\hline $\mathrm{C}$ & $\mathrm{Mn}$ & $\mathrm{S}$ & $\mathrm{P}$ & $\mathrm{Fe}$ \\
\hline max. 0.08 & max. 0.4 & max. 0.03 & max. 0.03 & remainder \\
\hline
\end{tabular}


Table 2. Mechanical properties of sheets tested.

\begin{tabular}{|c|c|c|c|c|c|}
\hline Sample orientation & $R_{002}(\mathrm{MPa})$ & $R_{m}(\mathrm{MPa})$ & $A_{50}(\%)$ & $K(\mathrm{MPa})$ & $n$ \\
\hline $0^{\circ}$ & 184.5 & 303.9 & 23.0 & 490.4 & 0.205 \\
\hline $45^{\circ}$ & 193.7 & 314.9 & 22.1 & 489.9 & 0.164 \\
\hline $90^{\circ}$ & 176.1 & 296.0 & 22.8 & 465.7 & 0.169 \\
\hline
\end{tabular}

The determnation of the strain hardening parameters is facilitated with the use of logarithmic fransformation of the Eq. (1):

$$
\log \sigma_{p}=\log K+\log \varepsilon^{n}
$$

The roughness parameters of as-received sheet surfaces were measured using a Talysurf $\mathrm{CCl}$ Lite optical profilometer. The topography of the DC04 sheet metal and main, standard 3D roughness parameters are shown in Fig. 2 and Table 3, respectively. The parameters measured were chosen based on the research conducted by Ham et al. [6] who concluded that the areal surface texture parameters are suitable for the characteristics of the sheet surfaces after SPIF. The roughness parameters of the deformed surfaces were measured using a Contour GT 3D optical microscope. The measurement was conducted at both inner and outer surfaces of drawpieces.

A hemispherical tool with a diameter of $d=7 \mathrm{~mm}$ and a radius of tool tip $r=3.5 \mathrm{~mm}$ made of high-speed steel is used in this work. In order to reduce frictional resistance, the full synthetic oil $75 \mathrm{~W}-85$ is used. Preliminary studies shown that this lubricant has a good ability to reduce the wear interaction of the tool tip with the inner surface of drawpiece. The lubricat in SPIF is important to obtain a smooth surface of part. The tests to form the conical truncated drawpieces (Fig. 3a) with the height of $70 \mathrm{~mm}$ were carried out on a conventional Computer Numerical Control (CNC) milling machine. The schematic view of the forming die is presented in Fig. $3 b$. The die is a flat surface with a hole of the diameter equal to $65 \mathrm{~mm}$. The samples with a diameter of $120 \times 120 \mathrm{~mm}$ were formed. The edges of the workpiece were clamped using ring blankholder.

The EdgeCAM software was used for generating of the tool path (Fig. 4) and NC code based on the geometry of the final part (Fig. 3a). According to the assumed strategy, the tool continuously indents into the sheet by step size of $0.5 \mathrm{~mm}$ and follows a helical path for the desired part (Fig. 2a). The forming strategy was programmed as "profile milling" [15] with helical tool path, tool rotational speed $n=87 \mathrm{rpm}$, feed rate $f=1500 \mathrm{~mm} \cdot \mathrm{min}^{-1}$.

The residual stresses were measured nondestructively using an X-ray diffractometer (XSTRESS3000) at the Universty of Rzeszów. A round collimator with a diameter of $2 \mathrm{~mm}$ was used. The maximum titling angles $\psi$ were $\pm 45^{\circ}$. The X-ray diffraction provides the residual stresses values from approximately $10 \mu \mathrm{m}$ depth of the

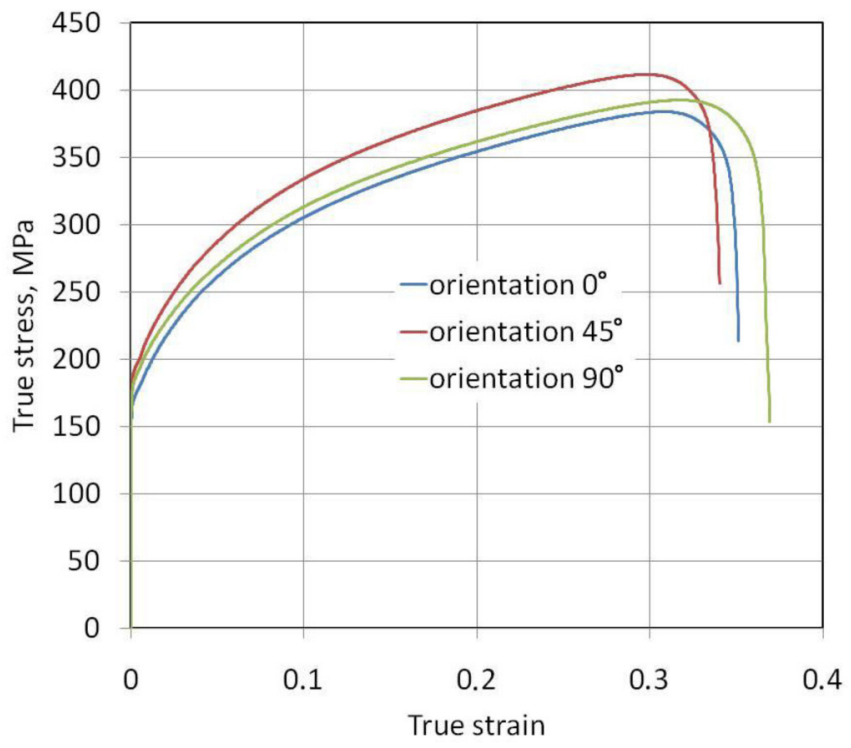

Fig. 1. True stress-strain relationship obtained from the uniaxial tensile test 


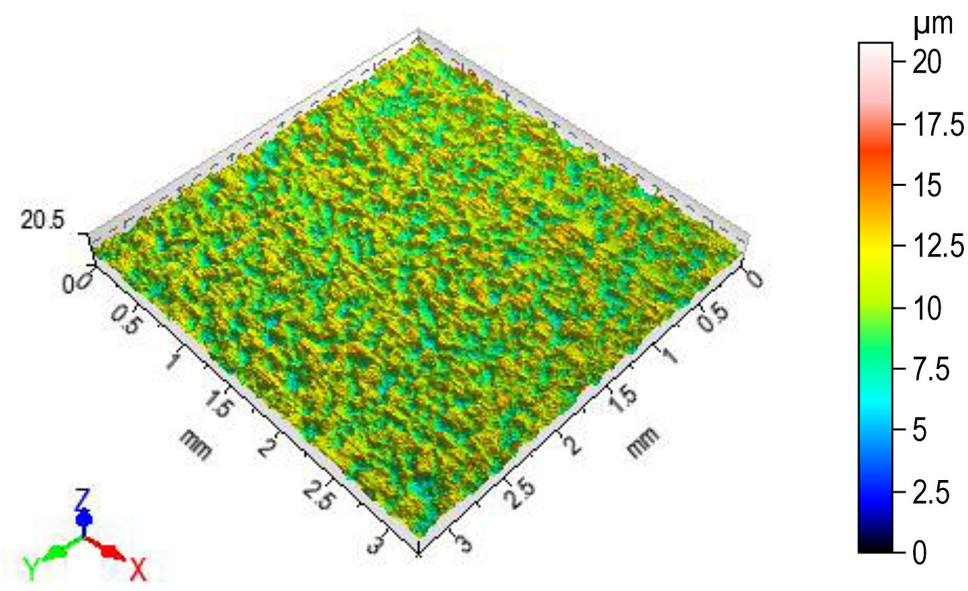

Fig. 2. Topography of the DC04 steel metal

surface layer of deformed material [17]. The Xray analysis of residual stresses is based on the Bragg's law. Bragg [4] developed a relationship explained why the cleavage faces of crystals appear to reflect the X-ray beams at certain incidence angles $\Theta$ :

$$
n \lambda=2 d \sin \Theta
$$

where: $d$ is the distance between the atomic layers in a crystal, $\lambda$ is the wavelength of the incident $\mathrm{X}$-ray beam and $n$ is an integer.

The fundamentals of the X-ray diffraction are graphically shown in Fig. 5. The strain in the crystal lattice was measured and the associated residual stress was determined based on the properties of the material (elastic constants). A linear elastic distortion of the appropriate crystal lattice plane was assumed. Changing the wavelength of the X-ray beam will also result in a different diffraction pattern. Diffraction pattern depends on the wavelength of the X-ray beam. The interplanar spacing of a material that is non-deformed will produce a specific diffraction pattern for the material. After the deformation of the material and its unloading, the contractions and elongations are produced within the crystal lattice. This process changes the inter-planar spacing of the $\{\mathrm{hkl}\}$ lattice planes and induces a change in the distance between the atomic layers in a crystal.
This results in a shift in the diffraction pattern. On the basis of this shift, the inter-planar spacing (strain) may be evaluated.

In this paper, the $\sin ^{2} \psi$ method, based on the diffraction theory and the strain analysis of the elasticity theory, was used. This method consists in the measurements of the diffraction line position at different angles $\psi$. Considering that the perpendicular component of the stress state on the surface of sheet metal is equal to zero, the strain component in an arbitrary direction $\varepsilon_{\varphi \psi}$ (Fig. 6) is [16]:

$$
\varepsilon_{\varphi \psi}=\frac{1+v}{E} \sigma_{\varphi} \sin ^{2} \psi-\frac{v}{E}\left(\sigma_{1}+\sigma_{2}\right)
$$

where: $E$ and $v$ are Young's modulus and Poisson's ratio, respectively; $\sigma_{1}$ and $\sigma_{2}$ are principal stress components; $\varphi$ is azimuthal angle; $\psi$ is polar angle (tilt), and $\sigma_{\varphi}$ is the analysed component of stress in the direction $\varphi$.

The Eq. (2) can be expressed in terms of $\mathrm{X}$-ray diffraction as:

$$
\varepsilon_{\varphi \psi}=\frac{d_{\varphi \psi}+d_{0}}{d_{0}}=-\operatorname{ctg} \theta_{0}\left(\theta_{\varphi \psi}-\theta_{0}\right)
$$

where: $\theta_{\varphi \psi}, \theta_{0}, d_{\varphi \psi}$, and $d_{0}$ are direction angles and interplanar disrtances, respectively.

Table 3. Basic roughness parameters and topography of the DC04 steel sheet tested

\begin{tabular}{|l|c|c|c|}
\hline \multicolumn{1}{|c|}{ Roughness parameter } & Denotation & Unit & Value \\
\hline The average roughness & $\mathrm{Sa}$ & $\mu \mathrm{m}$ & 1.31 \\
\hline The root mean square roughness & $\mathrm{Sq}$ & $\mu \mathrm{m}$ & 1.54 \\
\hline The highest peak of the surface & $\mathrm{Sp}$ & $\mu \mathrm{m}$ & 2.11 \\
\hline The maximum height of texture surface & $\mathrm{St}$ & $\mu \mathrm{m}$ & 10.31 \\
\hline The maximum pit depth & $\mathrm{Sv}$ & $\mu \mathrm{m}$ & \\
\hline
\end{tabular}


For the residual stress calculations, the following material properties were used: Young's modulus $\mathrm{E}=2.05 \mathrm{GPa}$ and Poisson's ratio $v=$ 0.3 . All of the measurements were performed at the three locations A, B, C, D (Fig. 3a) and the same direction.

\section{RESULTS AND DISCUSSION}

Both the inner and outer surfaces of the drawpiece are characterized by high values of roughness parameters, compared to the as-received surface roughness. This is due to the specificity of the SPIF method used, consisting in gradual deformations of the sheet metal due to local stretching of the material with a pin tool following a tool path controlled by a milling machine. The incremental sheet forming technology is a forming technology classified to the rapid prototyping methods which consist in a gradual adding of the material, layer-by-layer, until the desired form is created [8]. In this case of SPIFs methods, the inner surface of the drawpiece consists in linear cyclic grooves (Fig. 7b) the distribution of which mainly depends on the tool path strategy and vertical step size. The characteristic structure of the outer surface is the so-called orange peel roughening (Fig. 7a), which is associated with point interaction of the tool causing local deformation. Orange peel is associated with grain-scale roughening and morphological reliefs which dominate at the outer surface of the drawpiece when the tool forms only one side of the sheet. The roughening of the outer surface of the formed part is a microstructural defect which is most affected by the crystallographic distribution of grains. The orange peel effect is closely related to the strain rate; hence, the effect of forming parameters on
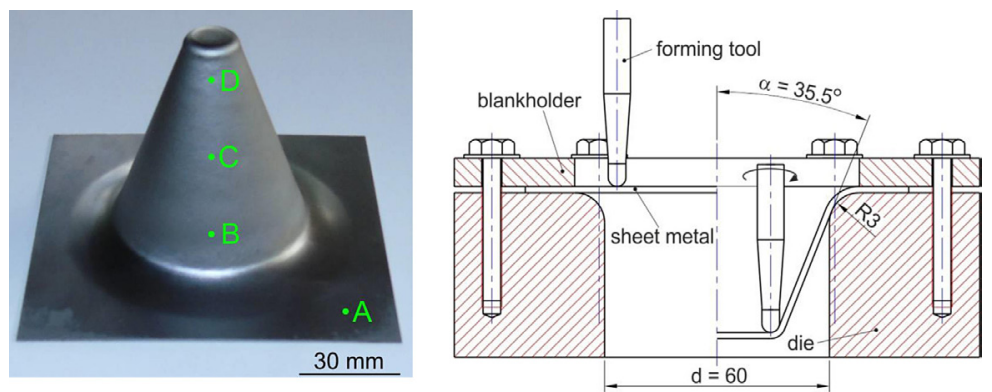

Fig. 3. (a) The conical truncated drawpiece and (b) geometry of the forming setup

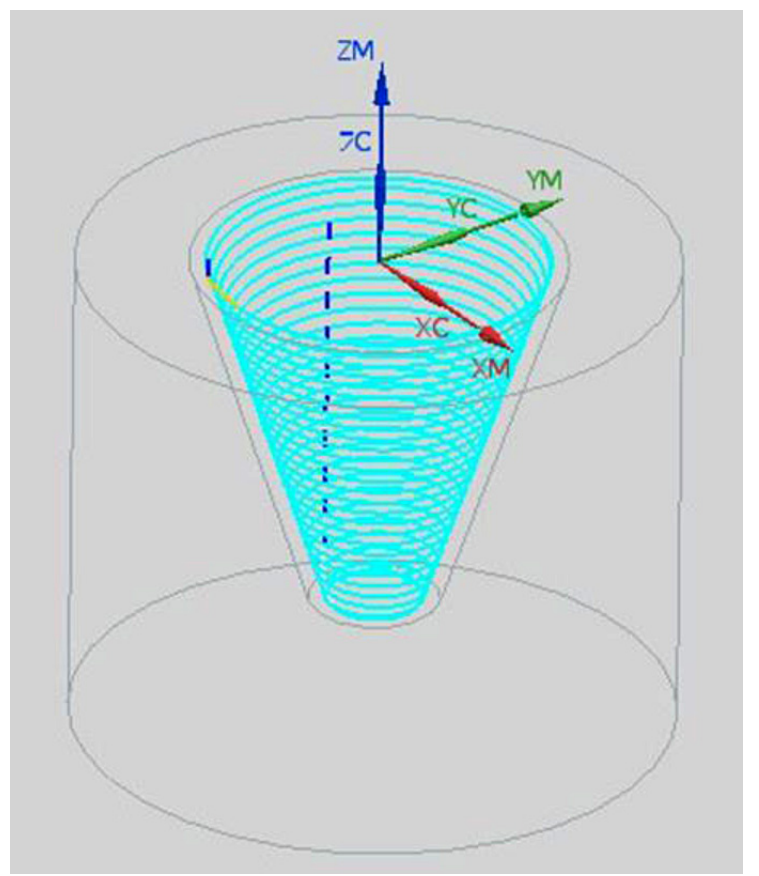

Fig. 4. Tool path generated for conical truncated drawpiece 


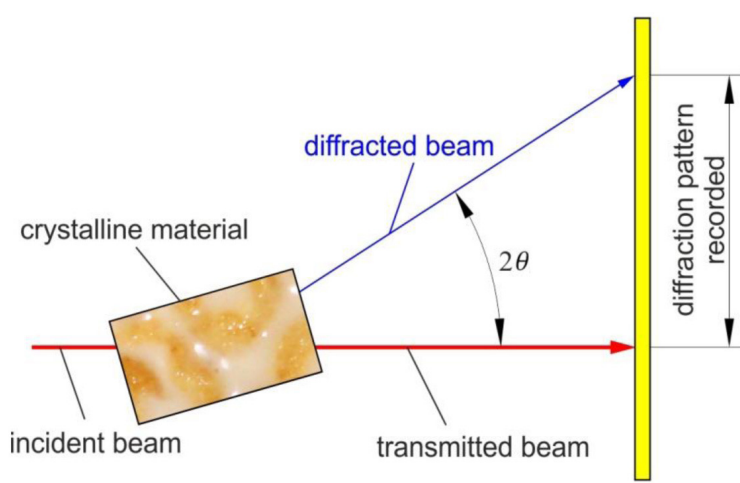

Fig. 5. X-ray diffraction methodology

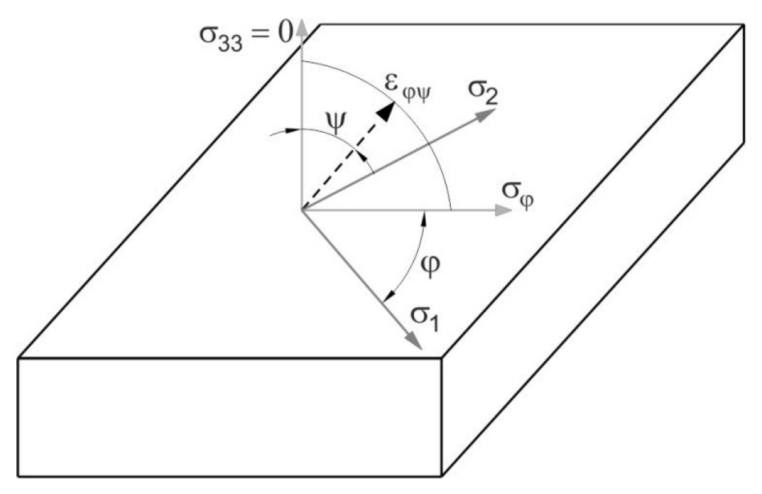

Fig. 6. Diffraction planes parallel to the surface and at an angle $\varphi \psi$.

uniform over the entire height of the conical truncated drawpiece. This is also confirmed by the results of the residual stress measurements (Fig. 10). At points B, C and D, which lie in the outer surface of the part, the tensile stresses were revealed. At point A lying in the vicinity of the flange of drawpiece, compressive residual stresses were found. The flange of the formed sheet was clamped between the surfaces of both die and blankholder to avoid the plastic deformation during the SPIF. Thus, the compressive residual stresses found in the flange can be a result of the manufacturing process of sheet metal, i.e. cold-rolling process. The deformation of the DC04 sheet in SPIF led to the intensification of the corrosion process [9]. Thus, the low-carbon steel sheets should be protected immediately after forming the anti-corrosion coating.

The tensile stresses revealed in the outer surface of the formed part lead to an increase in the distance between the grains in the material

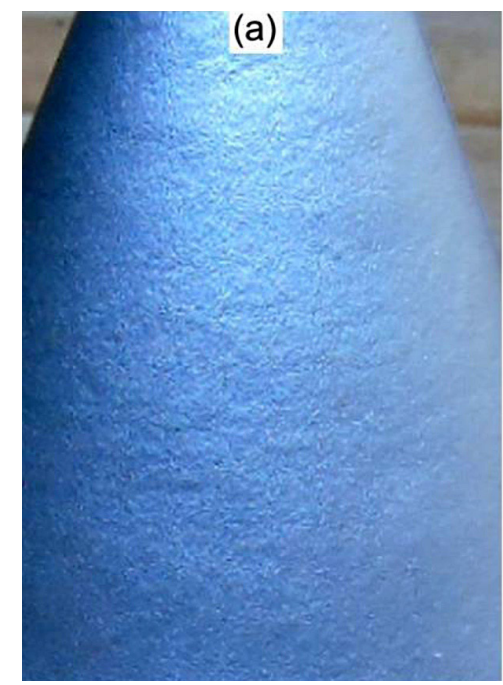

(b)

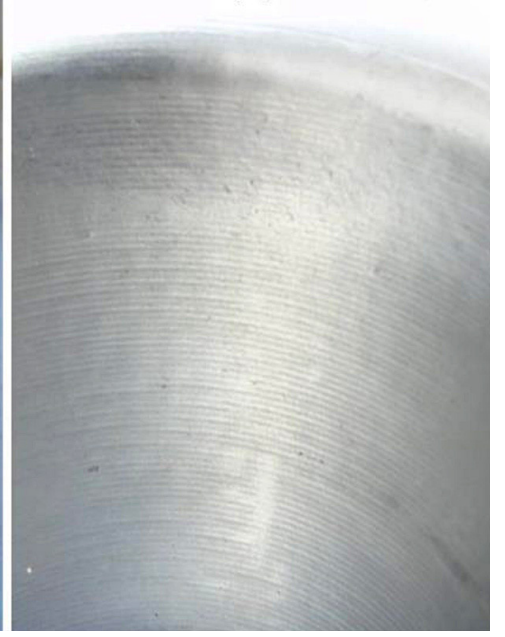

Fig. 7. Orange peel (a) and linear grooves (b) in the outer and inner surface of the drawpiece, respectively 

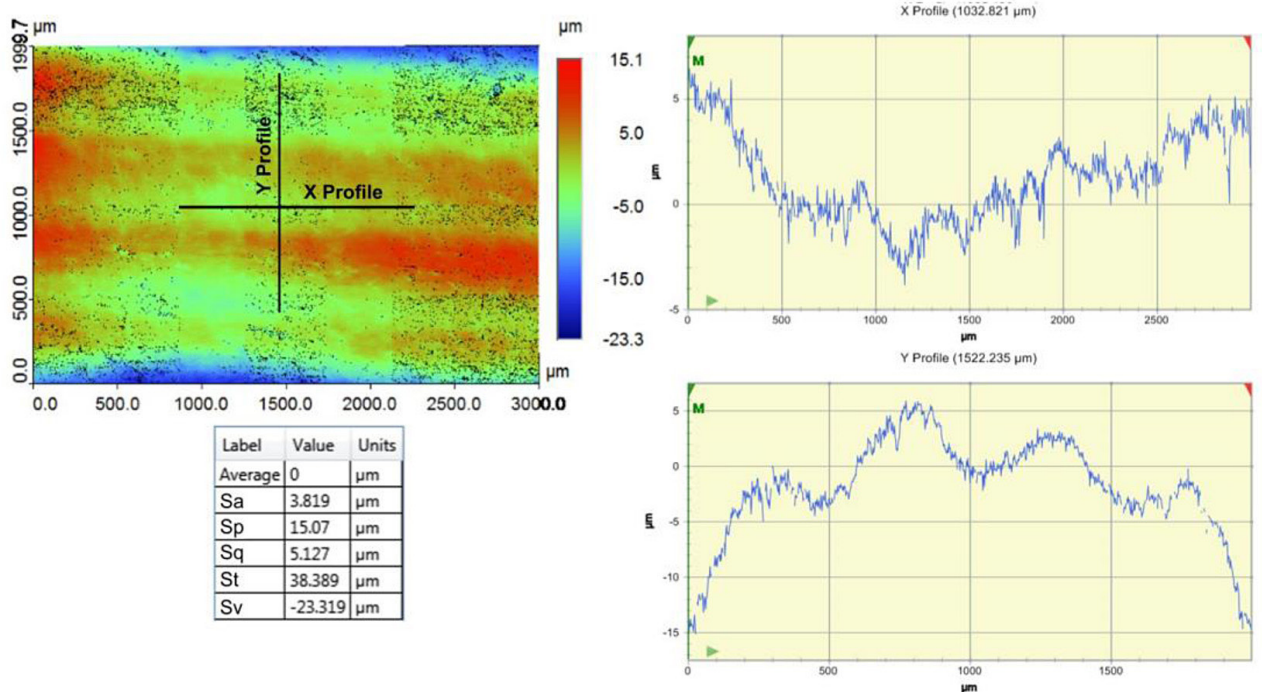

Fig. 8. Surface topography and values of the basic parameters measured at the inner surface of the drawpiece
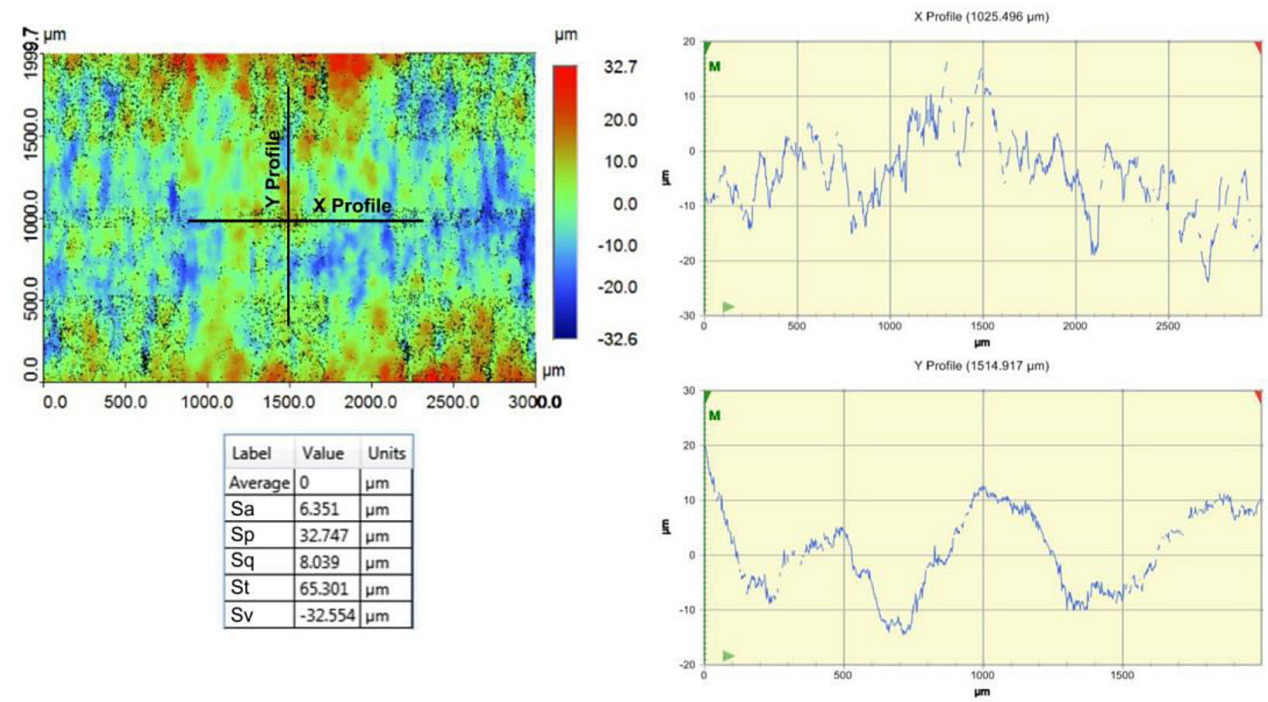

Fig. 9. Surface topography and values of the basic parameters measured at the outer surface of the drawpiece

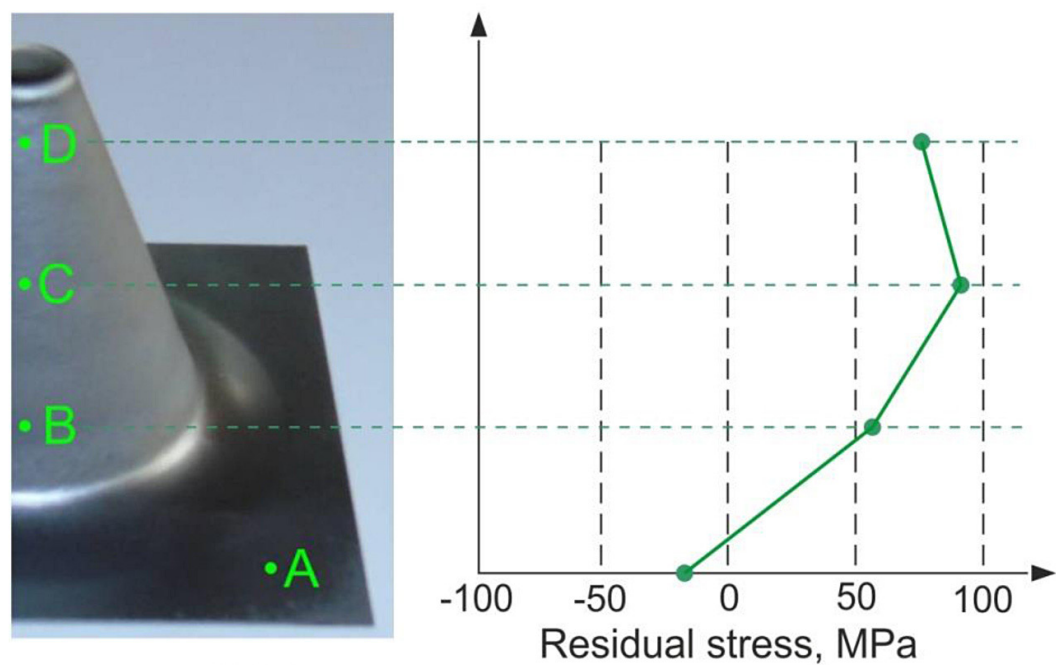

Fig. 10. The results of residual stress measurement 
structure, which can intensify the intergranular corrosion. This specific type of corrosion is an intense attack along the grain boundaries and it progresses very quickly, which leads to a significant reduction in the strength and susceptibility to plastic deformation of the material. When single point incremental formed parts are exposed to cyclic loads, the tool marks on the inner part of the formed part, and micro-cracks resulting from the tensile residual stresses may be a source of stress concentration and initiation of the fatigue cracks.

The geometric inaccuracies of the incrementally formed parts are mainly caused by a continuous local springback around the tool, and global springback [19]. The global springback results from the sudden decrease of stress as the deformation load from the tool is released. The deviations from the required nominal shape of the drawpiece caused by the springback phenomenon in the case of the incremental sheet forming method can be easily minimised or eliminated by a correction of the tool path.

\section{CONCLUSIONS}

The following observations and conclusions can be drawn based on the investigations:

1. In the conventional deep drawing processes, the surface stresses in the formed part largely depend on the lubricant used [18]. However, when the material is formed using ISF, the type of lubricant does not have a significant impact on the surface stress on the outer part of the drawpiece. The lubricant used mainly effects on the surface quality of the inner surface.

2. In the conventional deep-drawing process the rounded edge of the drawpiece bottom is critical in terms of the edge cracking possibility. Under the cold forming conditions, the intensive concentration of the tensile stresses exists in this region. The investigations of SPIF did not reveal the cracking of the at the edge of truncated cone which can be considered as the advantage of this technology.

3. A significant increase in the values of basic areal roughness parameters is revealed both in the inner and outer surface of the conical truncated drawpieces.

4. The results of the XRD measurements showed tensile residual stresses in the outer part of the conical part of the drawpiece when orange peel roughening was observed. The interaction between the tensile residual stresses and high roughness produced by the sheet metal defomation may be a source of the corrosion process intensification.

\section{REFERENCES}

1. Ai S., Lu B., Chen J., Long H., Ou H. Evaluation of deformation stability and fracture mechanism in incremental sheet forming. International Journal of Mechanical Sciences, 124-125, 2017, 174-184.

2. Aldo A., Ceretti E., Giardini C. Optimization of tool path in two points incremental forming. Journal of Materials Processing Technology, 177(1-3), 2006, 409-412.

3. Bedan A.S., Mohammed S., Kamal M. The effects of process parameters on residual stresses in single point incremental forming of A1050 aluminium using ANOVA model. Engineering Technology Journal, 35(1), 2017, 41-48.

4. Bragg W.H., Bragg, W.L. The reflexion of X-rays by crystals. Proceeding of the Royal Society A, 88(605), 1913, 428-38.

5. Durante M., Formisano A., Langella A., Minutolo F.M.C. The influence of tool rotation on an incremental forming process. Journal of Materials Processing Technology, 209(9), 2009, 4621-4626.

6. Ham M., Powers B.M., Loiselle J. Surface topography from single point incremental forming using an acetal tool. Key Engineering Materials, 549, 2013, 84-91.

7. Jiménez I., López C., Martinez-Romero O., Mares P., Siller H.R., Diabb J., Sandoval-Robles J.A., Elías-Zúniga A. Investigation of residual stress distribution in single point incremental forming of aluminum parts by X-ray diffraction technique. International Journal of Advanced Manufacturing Technology, 91, 2017, 2571-2580.

8. Khalil U., Aziz M.H., Jahanzaib M., Ahmad W., Husssin S., Hafeez F.: Effects of forming tools and process parameters on surface roughness in incremental sheet forming. Advances in Science and Technology Research Journal, 12(3), 2018, 75-95.

9. Klimek L., Was-Solipiwo J.; Dybowski K. Effect of aluminium and magnesium on the corrosion resistance of zinc coatings, Advances in Science and Technology Research Journal, 11(2), 2017, 28-32.

10. Kumar A., Gulati V., Kumar P. Investigation of surface roughness in incremental sheet forming. Procedia Computer Science, 133, 2008, 1014-1020.

11. Li Y, Liu F., Xu C., Zhai W., Zhou L., Li F., Li J. Investigation of the effect of process parameters on energy consumption in incremental sheet forming. Procedia CIRP, 80, 2019, 50-55. 
12. Lu B., Fang Y., Xu D., Chen J., Ou H., Moser N., Cao J. Mechanism investigation of friction-related effects in single point incremental forming using a developed oblique roller-ball tool. International Journal of Machine Tools and Manufacture 85, 2014, 14-29.

13. Maaß F., Hahn M., Dobecki M., Thannhäuser E., Tekkaya A.E., Reimers W. Influence of tool path strategies on the residual stress development in single point incremental forming. Procedia Manufacturing, 29, 2019, 53-58.

14. Maqbool F., Hajavifard R., Walther F., Bambuch M. Experimental investigation and finite element modelling of residual stress control in disc springs made of metastable austenitic stainless steel (MASS) using incremental sheet forming (ISF). Procedia Manufacturing, 29, 2019, 12-20.

15. Milutinovic M., Lendel R., Potran M., Vilotic D., Skakun P., Plancak M. Application od single point incremental forming for manufacturing of denture base. Journal of Technology of Plasticity, 39(2), 2014, 15-24.
16. Monine V.I., Filho J.C.P., Gonzaga R.S., Passos E.K.D., Assis J.T.: X-ray diffraction technique for residual stress measureent in NiCrMo alloy weld metal. Advances in Materials Science and Engineering, 2018, 2018, 8986423.

17. Sepsi M., Cseh D., Filep A., Benke M., Mertinger $\mathrm{V}$. Innovation methods for residual stress determination for the automotive industry. [in] Jármai K., Bolló B. Vehicle and Automotive Engoneering, Springer, 2017 p. 483-497.

18. Sherbiny M.E., Zein H., Abd-Rabou M., Shazly M.E.: Thinning and residual stresses of sheet metal in the deep drawing proces. Materials and Design, 55, 2014, 869-879.

19. Trzepieciński T., Lemu H.G. Effect of computational parameters on springback prediction by numerical simulation. Metals, 7, 2017, 380.

20. Xu D., Wu W., Malhotra R., Chen J., Lu B., Cao J. Mechanism investigation for the influence of tool rotation and laser surface texturing (LST) on formability in single point incremental forming. International Journal of Machine Tools and Manufacture, 73, 2013, 37-46. 